\author{
KRZYSZTOF KRAUZE \\ WALDEMAR RACCZKA \\ MAREK SIBIELAK \\ JAROSEAW KONIECZNY \\ DARIUSZ KUBIAK \\ HENRYK CULER \\ DANIEL BAJUS
}

\title{
Automated transfer point URB/ZS-3
}

\begin{abstract}
In the KGHM Polska Miedź S.A. mines, excavated material is transported by transport trucks to transfer points and then by belt conveyors to near-shaft storage reservoirs, from where the excavated material is transported to the surface by means of a shaft transport system. Transfer from the means of non-continuous haulage to the continuous transport systems takes place at transfer points, where the excavated material is divided into two fractions: oversized grain and undersized grain. The oversized excavated material (which stays on the grating) is subjected to a process of crushing with the use of jack hammers. The article describes the URB/ZS-3 device for the automatic cleaning of the grating at transfer points, and briefly describes the design and principle of operation of the device. It also presents the purpose of constructing a block-crushing device and the method of its automation.
\end{abstract}

Key words: mining, robotics, automation

\section{INTRODUCTION}

In the KGHM Polska Miedź S.A. mines, useful minerals are quarried using explosives. The excavated material is transported to the surface using haul trucks, conveyors, and vertical transport means; e.g., a skip. Transfer from the haul trucks to the belt conveyors happens at transfer points $[1,2]$. The excavated material supplied to these points is characterized by varying grain sizes, from $1 \mathrm{~mm}$ grains to blocks with a volume of one cubic meter. Because large blocks of excavated material can damage the conveyor, screens called "gratings" are mounted at the transfer points. The excavated material that stays on the grating is subjected to a process of crushing with the use of hydraulic jack hammers $[3,4,5]$. With the appropriate manipulation of the hammer, the operator breaks the oversized grain until it is broken down to a size that allows it to escape through the meshes in the grating.
At present, most of the transfer points are equipped with hydraulic hammers controlled from the operator's station located next to the transfer point. Using different techniques for removing oversized grains from the grating, the operator reveals oversized blocks to break them down to a size that allows them to be transported by the belt conveyor. The operator who works directly at the transfer point (i.e., in the local control cabin placed directly at the grating) is exposed to a number of adverse factors such as noise, dust, vibrations, high temperatures, and humidity as well as risks from the rock mass (cave-ins, rock bursts, etc.).

Considering the above risks, a remote hammer control exercised from within a room located at a safe distance (of even a few kilometers away) from the transfer point was developed and manufactured to dramatically reduce the risks. The operator - who is away from the transfer point - controls the operation of the transfer point remotely using a remote-control 
panel (Fig. 1). Such a block-crushing device (Polish: Urządzenie do Rozbijania Brył - URB) is manufactured by KGHM ZANAM S.A., and a remote-controlled version of the device is named «URB/ZS-1.» Another version of the block-crushing device is the URB/ZS-3, which autonomously cleans the grating at a transfer point.

Relieving the operator by introducing a fully automated transfer point will increase the operator's efficiency, as the operator's job will be to supervise the operation of the equipment. This will enable the operator to control a greater number of transfer points than at present. The operator will intervene in the operation of the transfer points only at the event of failure. It was assumed that at least 80 percent of the activities associated with block crushing will be carried out automatically. And as for the remaining 20 percent of the time, the operator will intervene in the operation of the autonomous system by taking over the control of the transfer point. It was assumed that the operator will intervene mainly in abnormal situations. Therefore, the system gives the operator the possibility of taking over the remote control of the boom.

A consortium composed of KGHM ZANAM S.A. (Leader), AGH University of Science and Technology in Krakow, and KGHM CUPRUM Ltd Research and Development Center was established to conduct development of transfer point.

\section{SOFTWARE}

The constructed control system operates on the basis of a freely programmable controller that embeds a real-time operating system. This system ensures the real-time synchronization of the control system. After power on, a control program automatically starts in the controller. The concept of the operation of the program is shown in Figure 1. As can be seen, the operator is always given priority, and it is the operator who decides whether they will control the hammer manually (locally or remotely) or turn on the automatic mode. If the operator decides to select automatic operation, they turn on the automatic AHC system. The operator selects the type of operation based on the information from the cameras and the information displayed on the touch screen (as shown in Figure 2).
In Figure 1, it can be seen that the AHC system controls the boom (URB/ZS-3) using the control signals determined on the basis of the current system status and setpoint. Figure 3 shows the block diagram of the AHC system. As can be seen, it consists of two layers: the master control layer and the direct control layer. In the master layer, the control system generates a trajectory that will be executed by the direct control system after the shape and dimensions of the spoil pile have been identified,. The trajectory was developed by using heuristic algorithms and observing the grating-cleaning process. The trajectory is executed in the direct control layer.

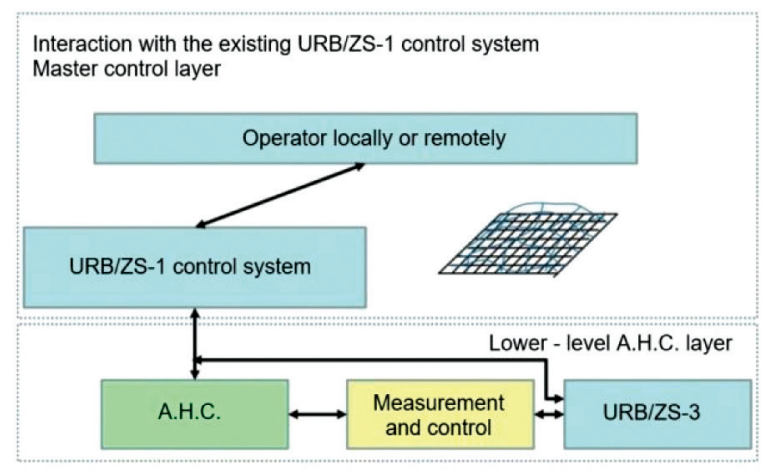

Fig. 1. Concept of Automatic Hammer Control (AHC) system

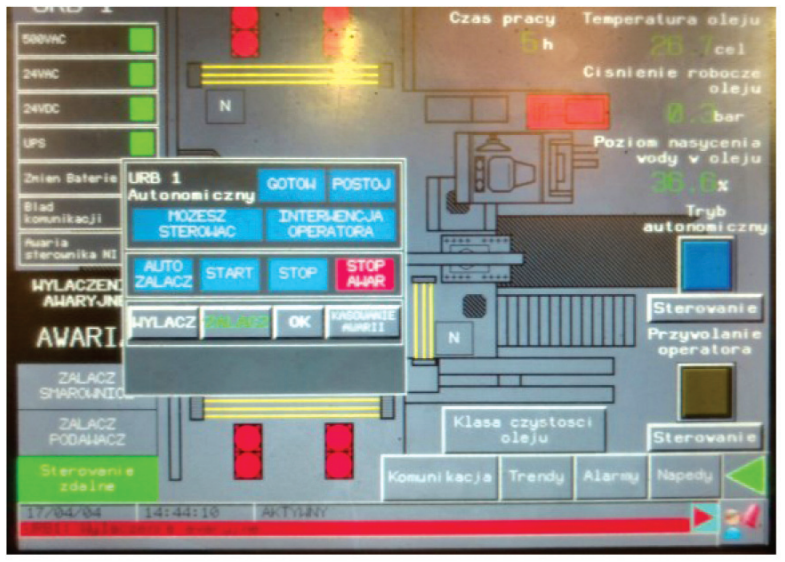

Fig. 2. View of GOI (graphic operator interface)

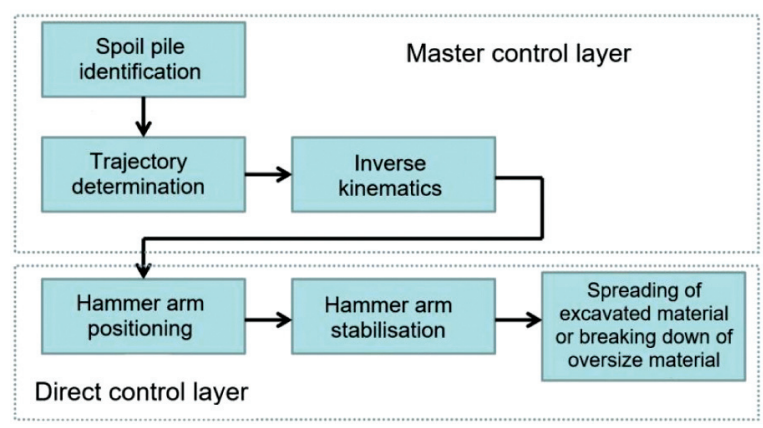

Fig. 3. Block diagram of AHC system 
As can be seen, four main modules can be distinguished in the AHC system:

- excavated material identification module,

- module for determining hammer-motion trajectory,

- inverse kinematics module,

- direct control module.

Spoil pile identification is the basic task of the $\mathrm{AHC}$ system. It is very important that the appropriate equipment is selected for this task. As a result of completing the task, the excavated material remaining on the grating should be identified. Since the data on the shapes and positions of the spoil piles (or on the shapes and positions of the oversized grains) is supplied in digital form to the control system, the excavated material remaining on the grating can be removed. Once equipped with the shape identification system, the URB device becomes a robot that autonomously detects the position of the excavated material on the grating and then takes steps to remove the said material from the grating.

Because the data on the parameters of the excavated material is crucial for the operation of the URB/ZS-3-type robot, a range of conceptual works were carried out to identify the required features of this equipment. The established objective, conditions in the transfer points, size of the grating, length of the post-mining pit, and requirements of the control system were considered.

Figures 4 and 5 below show, respectively, a real view of the excavated material on the grating and its electronic image after scanning. Based on this data, the robot defines the trajectory along which it will move.

The module for determining the hammer-motion trajectory is a closed part of the program, working in a real-time system. It works in a sequential manner and executes the selected scenario. The scenarios were developed based on observations of the operation of the autonomous system. The operator selects

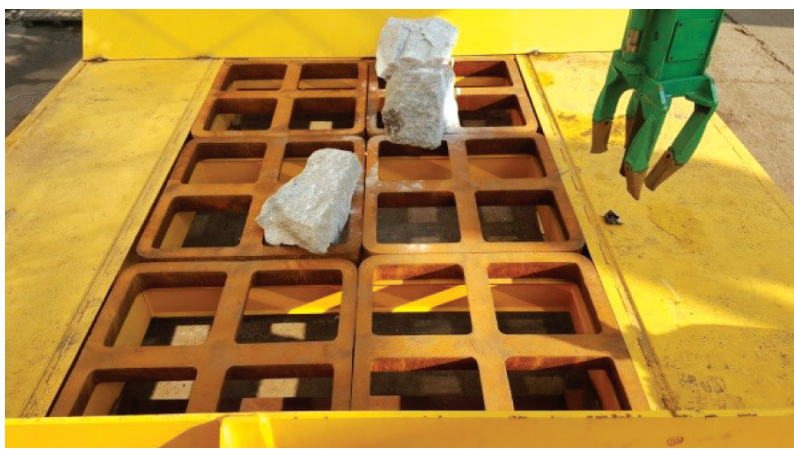

Fig. 4. View of excavated material on grating the type of scenario, and the AHC system executes it. Because the arrangement of the excavated material changes while the hammer is in operation, the arrangement of the excavated material is identified on a continuous basis. When there are changes in the arrangement of the excavated material, the hammermotion trajectory can change at any time, and it actually changes. This happens for many reasons, because when the trajectory is being executed, different types of additional mechanisms are at work; e.g., the detection of oversized material. As a result of its response to changes in the arrangement of the excavated material, (or changes in other parameters of the excavated material), the module for determining the motion trajectory generates new motion trajectories of the boom with the hammer. This feature of the algorithm makes the AHC-equipped URB a device that adapts to changing environmental conditions. The system carries out these tasks autonomously; however, the operator can interrupt the operation of the system at any time and take over control of the hammer. This manner of operation is possible thanks to the proposed structure of the URB/ZS-3 control system (which is shown in Figure 1). In this structure, the remote-control system (which is the master system) is connected to the AHC system. This enables the operator to know the status of the device and stay informed about any undesirable or emergency statuses. Feedback from the AHC system enables the operator to effectively supervise the status of the device and, if necessary, take full control over it.

The trajectories generated on the basis of the identified excavated material are transferred to an inverse kinematics module. This module, using the implemented hammer kinematics model, determines the setpoint outward strokes of the boom actuators.

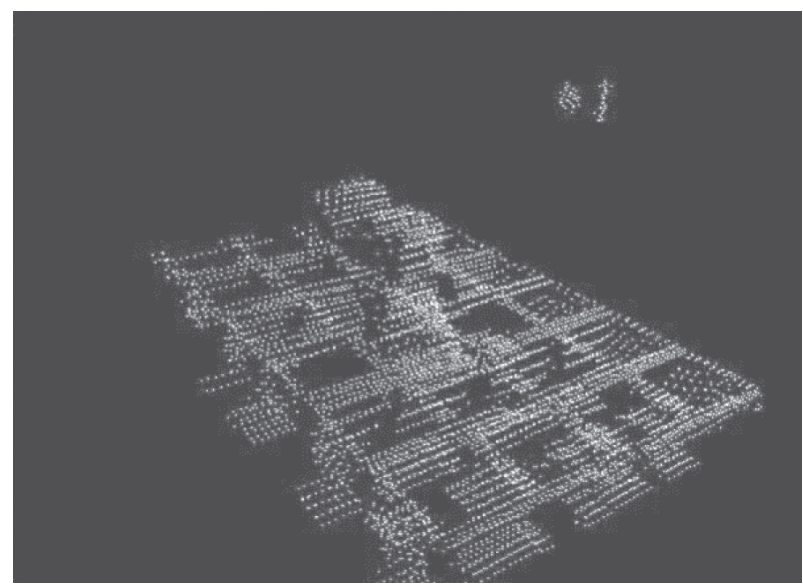

Fig. 5. View of scanned excavated material on grating 
These are the setpoints for the direct control module. This structure allows one to easily control the correctness, consistency, or continuity of the trajectories.

The setpoints for the actuators (determined in the inverse kinematics module) are generated by the regulators (Fig. 7) implemented in the direct control module. This module deals with generating setpoint positions of the actuators using the regulators implemented in FPGA.

\section{AUTOMATIC CONTROL SYSTEM USED TO CONTROL THE BLOCK-CRUSHING DEVICE}

The developed system for the automatic cleaning of the grating at transfer points was implemented in a remote-controlled version of the block-crushing device - URB/ZS-1. This device is equipped with a PLC, remote control panel (Fig. 6), and electrically-controlled actuators. Because the URB/ZS-1 was implemented for operation in a mine, the device pro-

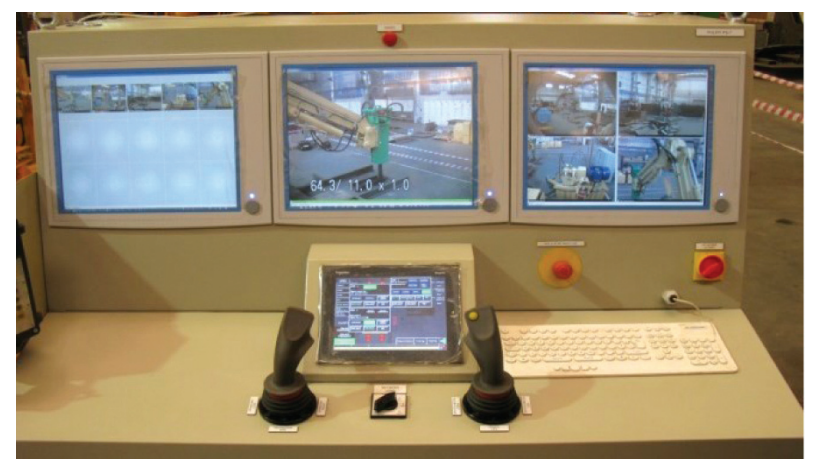

Fig. 6. General view of operator panel vides a great basis for developing the aforementioned machine further and equipping it with an automatic control system that will make it work in an autonomous manner.

After analyzing and testing the mechanical and electrical design of the URB/ZS-1 and the grating-cleaning technology, the main assumptions for the automation system were made:

- the control system must operate autonomously,

- the operator must be able to take over the control and turn off the autonomous system at any time,

- at least 80 percent of the activities associated with block crushing will be carried out automatically by the device,

- for the remaining 20 percent of the time, the operator will intervene in the situation at the grating,

- the process of removing the excavated material from the grating will last not more than ten-odd minutes,

- structural changes must be as minor as possible as compared to the URB/ZS-1 system.

The direct control layer shown in Figure 3 is composed of freely programmable controller and sensors or transducers mounted on the boom and in the hydraulic system. The automatic control system is presented in more detail in Figure 7. It consists of a measurement system for measuring the displacement of the actuator as well as the angular displacements of the boom joints. This redundancy at the system-testing stage was to reduce the potential risks of the project. In the diagram, it can be seen that the signals from the excavated material scanning device, signals from the operator, and current hammer status

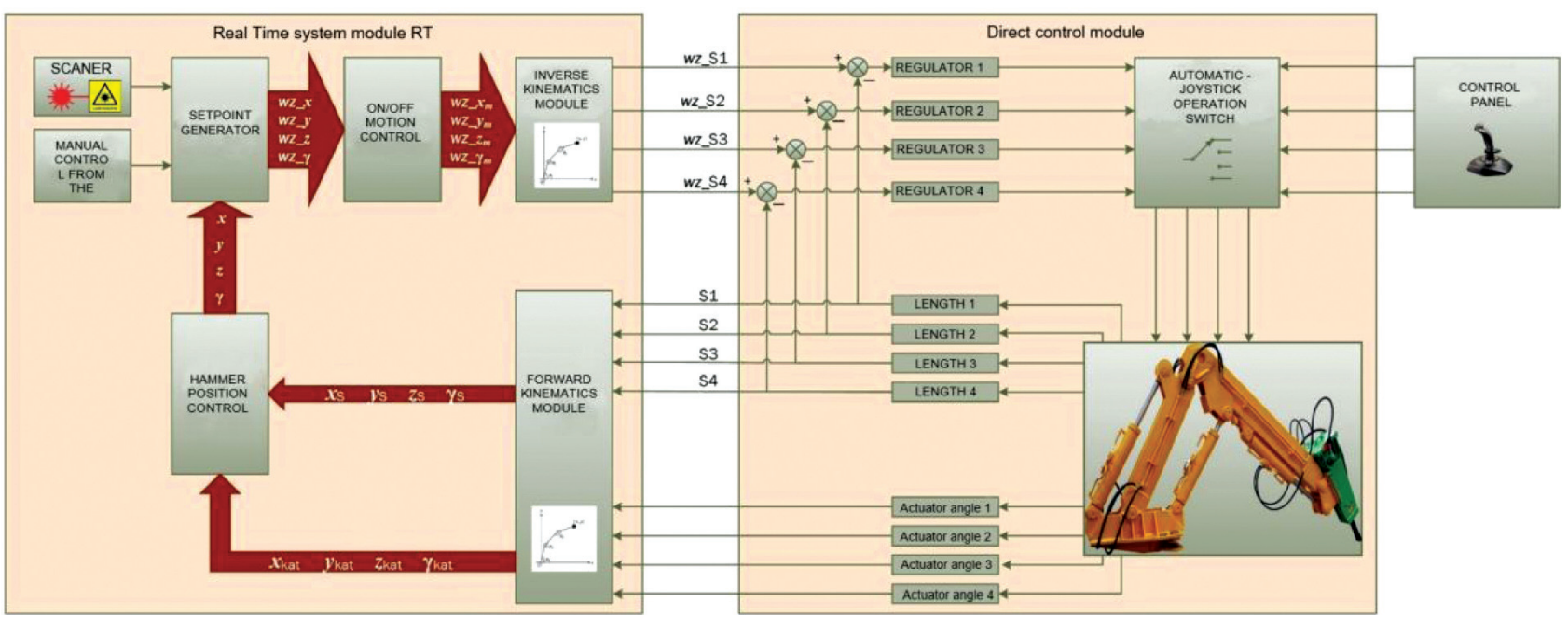

Fig. 7. Schematic diagram of control system 
are processed in the unit named the "setpoint generator." The unit determines the setpoints for the direct control module.

The setpoint is transferred to the summation node in which the error signal is calculated. Based on the error signal, the regulators determine the control signals that control actuator valves S1, S2, S3, and S4. The control signals controlling the solenoid valves pass through the "Automatic - Joystick operation switch" unit, which is used to select between automatic operation and manual control by the operator.

\section{TESTING}

The constructed system was mounted on a test stand at KGHM ZANAM S.A. (Fig. 8). The stand was activated in a remote-controlled version. After carrying out test runs, it was undertaken to start the automation system (that is, the AHC system). For this purpose, all of the measurement lines were checked, the scales were subsequently introduced, and the entire measurement system was tested. The tests included tests of the ranges of motion of the actuators, the measuring ranges of the pathway transducers, the levels of interference, and the static and dynamic properties of the system.

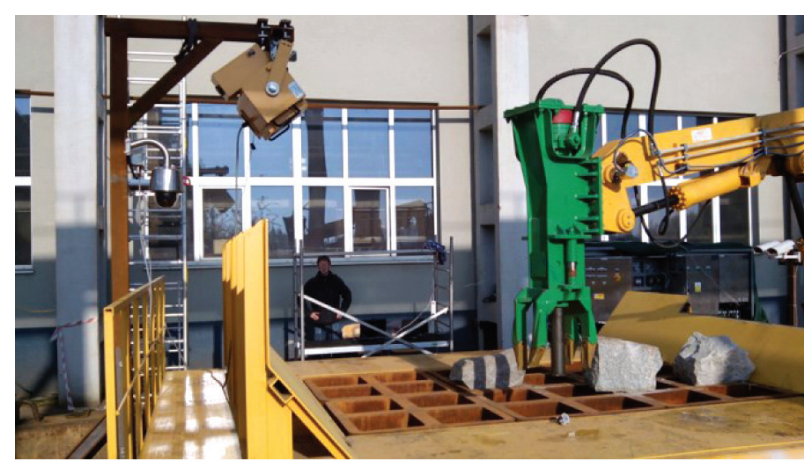

Fig. 8. URB device-testing stand

Next, the control system was tested, and the signals controlling the solenoid valves were also checked. The "manual" control was tested using the computer by controlling the boom. The control range was checked, and the parameters of the regulators of the actuator control lines were subsequently set. The next step was to start the direct regulator. The regulator settings were verified and adjusted, and the step responses for all of the control channels were checked.
After starting the direct control layer, it was undertaken to start the forward kinematics module and inverse kinematics module, motion control module, trajectory determination module, and scanning and analysis modules.

The following tests on the regulatory systems were performed:

- range of motion of the individual actuators,

- speed of the actuators,

- interference in the measurement lines and crosstalk between them,

- interference during motion.

After starting and testing all of the modules of the AHC system, it was undertaken to test the entire system. First, the scanning system was calibrated. Next, the grating-scanning system was tested, and the systems of coordinates were synchronized. After completing the above-mentioned basic equipment and software tests, a range of tests on the automatic operation were carried out. These included testing of the work of two scenarios:

- random spreading of excavated material,

- labyrinth spreading of excavated material.

\section{SUMMARY}

This paper presents an autonomous robot system for rock crushing. It shows the scope of works carried out and briefly describes the automation system and the structure of the control program. It describes the undertaken tests, which included measurement system tests, control system tests, test runs, verification of the kinematic models, and kinematics module tests as well as control module tests, scanning system tests, and tests on the connection between the controller of the AHC system and the PLC. The works carried out have shown that the system executes the tasks in line with the assumptions. The systems of excavated-material identification, trajectory determination, and trajectory implementation work well. The conducted research has shown that the system is able to satisfactorily remove excavated material of a significant size from the grating. The next step is to install the system on a real grating in accordance with the requirements of the future user to check the capabilities of the system under actual mining conditions. 


\section{Acknowledgements}

This work has been financed under the CuBR Program financed by the National Center for Research and Development - contract no. CuBR/II/1/NCBR/ 2015 and KGHM Polska Miedź S.A. - contract no. KGHM-BZ-U-0737-2015.

\section{References}

[1] Krauze K., Kotwica K., Mendyka P., Bołoz Ł., Kulinowski P., Kasza P., Nawrocki M., Feliks J., Tomach P., Władzielczyk K., Kipczak P.: Wybrane problemy urabiania, transportu i przeróbki skat trudnourabialnych. Tom 1, Wydawnictwa AGH, Kraków 2016.

[2] Krauze K., Orozco Álvarez D., Bołoz Ł, Iwaniec M., Krauze K., Sidor J., Tomach P., Wydro T. et al.: Problemy bezpieczeństwa w budowie i eksploatacji maszyn i urzadzeń górnictwa, "Mechanizacja, Automatyzacja i Robotyzacja w Górnictwie. Monografia 2012", Ledziny 2012.

[3] Krauze K., Pluta J., Podsiadło A., Micek P.: Badanie ciężkich młotów hydraulicznych, "Maszyny Górnicze" 1996, 5: 62-71.

[4] Krauze K., Laska Z.: Diagnozowanie młotów Roxon i Rammer na podstawie badań stanowiskowych, "I Międzynarodowa Konferencja Techniki Urabiania: TUR 2001. Monografia”, Kraków - Krynica 2001: 442-448.

[5] Krauze K.: Experimental determination of impact energy of hydraulic hammers, "The Archive of Mechanical Engineering" 2000, 47, 1: 21-32.
[6] Krauze K., Stopka G., Rączka W.: Design and test result of the new solution hydraulic roof support for low seams, "International Multidisciplinary Scientific GeoConference SGEM" Albena, Bulgaria 2017, 17, 13: 189-196.

[7] Sibielak M., Rączka W., Konieczny J., Kowal J.: Optimal control based on a modified quadratic performance index for systems disturbed by sinusoidal signals, "Mechanical Systems and Signal Processing" 2015, 64-65: 498-519.

KRZYSZTOF KRAUZE, prof. WALDEMAR RACZZKA, D.Sc., Eng. MAREK SIBIELAK, D.Sc., Eng. JAROSEAW KONIECZNY, D.Sc., Eng. Faculty of Mechanical Engineering and Robotics AGH University of Science and Technology in Krakow Aleja Adama Mickiewicza 30, 30-059 Krakow, Poland \{krauze,wraczka, sibielak, koniejar\}@agh.edu.pl

DARIUSZ KUBIAK, M.Sc., Eng. HENRYK CULER, M.Sc., Eng. DANIEL BAJUS, M.Sc., Eng. KGHM ZANAM S.A. ul. Kopalniana 7, 59-101 Polkowice, Poland \{dariusz.kubiak1, henryk.culer, daniel.bajus\}@kghmzanam.com 